\title{
Influências teóricas do Professor Aldo Barreto na Ciência da Informação: uma análise da genealogia acadêmica
}

\author{
Theoretical influences of Professor Aldo Barreto in Information Science: an analysis of \\ academic genealogy
}

\author{
Rene Faustino Gabriel Junior \\ Doutor em Ciência da Informação \\ Universidade Federal do Rio Grande do Sul \\ rene.gabriel@ufrgs.br \\ Leilah Santiago Bufrem \\ Doutora em Ciência da Informação \\ Universidade Federal de Pernambuco \\ santiagobufrem@gmail.com
}

\begin{abstract}
Resumo
O Prof. Aldo Barreto (AB) foi um dos fundadores da Ciência da Informação do Brasil. Com o objetivo de reconhecer a valorização do trabalho acadêmico de $A B$ e a produção científica dele decorrente, assim como a influência que exerceu e vem exercendo sobre as posições dos pesquisadores descendentes, cujas atividades acadêmico-científicas estão oficialmente vinculadas ao pesquisador em foco, apresenta uma metodologia com potencial de ser adotada em outros estudos, com uso de estudos de citação. Identifica 15 orientandos, recorrendo ao Currículo Lattes de Aldo Barreto, assim como todas as produções de $A B$ e de seus orientandos de doutorado indexadas na Base Brapci, recorrendo aos artigos completos para análise de citação. Do total de 2.480 referências nos trabalhos de $A B$, identifica 153 autores com duas ou mais citações. Utiliza os mesmos procedimentos para estudar a bibliografia dos orientados e adota o software Matchword (coincidências de palavras), que retorna às palavras comuns e a sua frequência quando comparado às referencias de dois autores. Com esses dados, gera uma matriz dos autores citados por $A B$ e seus orientandos, para possibilitar a análise dos dados. Destaca as obras de Farradane, Bush, Derrida, Habermas, Levy, Lancaster, Otlet, Simon e Foucault como bases intelectuais de $A B$. Percebe o peso da literatura internacional como referencial do grupo, destacando o próprio $A B$ e Mueller, entre os autores nacionais. Conclui que estudos como este permitem aferir sobre a influência mútua entre pesquisadores da linha genealógica acadêmica e seus referentes teóricos, assim como para tornar visível a evolução e disseminação dos temas e áreas do conhecimento privilegiados e as opções metodológicas selecionadas.
\end{abstract}

Palavras-chave

Produção científica. Genealogia acadêmica. Estudos métricos de informação. Pesquisadores Sênior. Aldo Barreto.

\begin{abstract}
Prof. Aldo Barreto (AB) was one of the founders of Information Science in Brazil. With the objective of recognizing the value of Aldo Barreto's academic work and his scientific output, as well as the influence he has exerted and has been exerting on the positions of the descendant researchers whose academic-scientific activities are officially linked to the researcher in focus, presents a methodology with potential to be adopted in other studies. It identifies 15 advisees, using the Curriculum Lattes of
\end{abstract}


Aldo Barreto, as well as the productions of $A B$ and its doctoral orientations of indexed in Brapci Base, using the complete articles to organize the citations. From the total of 2,480 references in $A B$ works, it identifies 153 authors with two or more citations. It uses the same procedures to study the bibliography of the oriented ones and adopts software match word, developed, that returns to the common words and their frequency when compared to the references of two authors. With these data generates an array of authors cited by $A B$ and your doctoral students, to enable the analysis of the data. It emphasizes the works of Farradane, Bush, Derrida, Habermas, Levy, Lancaster, Otlet, Simon and Foucault like intellectual bases of $A B$. It perceives the weight of international literature as reference of the group, highlighting $A B$ and Mueller himself, among the national authors. It concludes that studies such as this allow us to gauge the mutual influence between scientific genealogy and its academic references, as well as to make visible the evolution and dissemination of the privileged themes and areas of knowledge and the selected methodological options.

\section{Keywords}

Scientific production. Academic genealogy. Metric information studies. Senior Researchers. Aldo Barreto.

\section{INTRODUÇÃO}

Estudar o processo de institucionalização da Ciência da Informação no Brasil tem sido um desafio devido ao amplo universo de instituições e pesquisadores da área, cuja produção científica vem se ampliando significativamente. O conjunto dos pesquisadores destacados entre seus pares, contribuindo para o fortalecimento dos grupos e instituições de ensino em que atuam, tem recebido apoio do Conselho Nacional de Desenvolvimento Científico e Tecnológico (CNPq), cuja ação de fomento afeta as estruturas formativas, representativas e de avaliação da área. Entre esses pesquisadores, destacam-se aqueles aqui denominados de históricos, pelo alcance substancial e temporal de sua contribuição à área do conhecimento.

Esta pesquisa fundamenta-se no pressuposto de que a produção da literatura científica gera reflexões em prol da renovação das estruturas de domínios, a partir da constituição de uma linha genealógica científica específica do campo em que atuam os pesquisadores. Acredita-se que a distinção atribuída àqueles que alcançam um elevado capital científico reforça a ideia de que "a vida do indivíduo não pode ser compreendida adequadamente sem referência às instituições nas quais sua biografia se desenrola" (MILLS, 1975). Esse argumento, ilustrado pelo trabalho de Andraos (2005) e pelas reflexões de Mena-Chalco (2016) sobre a origem, evolução e disseminação de áreas do conhecimento, salienta que os estudos de genealogia no contexto acadêmico têm se revelado importantes ferramentas para investigar a produção científica, os autores, os eventos e as relações presentes na conjuntura científica do campo ou domínio pesquisado. Andraos (2005) destaca sua importância para a compreensão da evolução da história científica e para a identificação de contextos e circunstâncias das descobertas, assim como das relações entre os pesquisadores, suas ideias e o fluxo de conhecimento entre eles e seus inspiradores. A construção do objeto da pesquisa científica genealógica, relacionada à investigação dos ascendentes e descendentes de um pesquisador, prevê a identificação dos graus de vínculos entre os indivíduos, os quais podem ser encontrados nos registros históricos, ou seja, em documentos que evidenciem suas ligações (ROSSI; MENA-CHALCO, 2014).

Com esses pressupostos, reconhece-se a necessidade de as investigações se orientarem pelos registros de permanência dos referenciais teóricos que materializam valores de 
um domínio e, desse modo, se tornam legitimados pelo coletivo acadêmico. Para essa organização dos princípios e arcabouços teóricos, o exercício de leitura e análise das descendências na literatura produzida é estimulante. Por ele são reconhecidas as relações entre autores nas diferentes gerações, acrescidas de informações aos repertórios pessoais e institucionais, assim como levantados outros textos de interesse para que se possa conhecer a produção científica, tanto em termos de seu significado para o desenvolvimento do campo da Ciência da Informação, quanto de suas vertentes temáticas e concentrações de interesses.

Para este estudo, autores são denominados agentes, conforme concepção de Bourdieu (1996), já que atuam no campo e adotam um senso prático, sistema adquirido de preferências, de classificações e de percepções (BOURDIEU, 1996, p. 44). Ao incorporarem um habitus gerador, seja pelo convívio com seu ascendente, seja pelas experiências vivenciadas no mundo acadêmico, os agentes passam a condicionar as aquisições mais novas pelas mais antigas. Percebem, pensam e agem dentro da estreita liberdade, dada pela lógica do campo e da situação que nele ocupam. O habitus não é, portanto, um destino, pois preserva uma margem de liberdade ao agente, sempre condicionada às regras conferidas pelo campo em que se insere, associadas à trajetória da existência social dos agentes.

Pode-se questionar sobre a efetividade dessa contribuição e se é possível reconhecer a força dessa influência a partir de um modelo de pesquisa que facilite o reconhecimento da atuação concreta de um pesquisador em sua descendência. Para responder a esta indagação, foi selecionado um pesquisador com mérito científico e reconhecido institucionalmente na área da Ciência da Informação, Aldo Albuquerque Barreto, partícipe da elite da produção científica no Brasil, Pesquisador Sênior do Conselho Nacional de Desenvolvimento Científico e Tecnológico (CNPq).

O Professor Aldo de Albuquerque Barreto foi um pioneiro na construção da ciência da informação brasileira. Além de único Pesquisador Sênior do CNPq da área de Ciência da Informação, título concedido, em 2011, em caráter vitalício, como "reconhecimento a uma vida dedicada à pesquisa em ciência e tecnologia", foi presidente nacional da Associação Nacional de Pesquisa e Pós-Graduação em Ciência da Informação (Ancib), no período de 1997 a 2003. Integrou o grupo de trabalho de edição do Livro Verde do Programa Sociedade da Informação no Brasil, criou e foi editor por 14 anos do periódico Datagramazero, manteve uma importante lista de discussão no início dos anos 2000 e publicou diversos artigos e capítulos de livros. Graduado em Economia pela Universidade Federal do Rio de Janeiro (1968), Mestrado (1968-1969) e Doutorado (1975-1982) em Information Science, ambos pela The City University of London, da Inglaterra.

Retornando ao Brasil, vinculou-se ao Instituto Brasileiro de Informação em Ciência e Tecnologia (Ibict), atuando junto à Coordenação de Ensino e Pesquisa, Ciência e Tecnologia da Informação, no Núcleo do Rio de Janeiro, como pesquisador Titular, contribuindo para a implantação do Programa de Pós-Graduação em Ciência da Informação do órgão, compreendendo um doutorado, um mestrado e curso de especialização. Atuou, desde então, em programas de Pós-Graduação em Ciência da Informação, no Rio de Janeiro pelo Convênio do Ibict com a UFRJ e a UFF dedicando-se à docência na pós-graduação e formação de pesquisadores, tendo orientado dissertações e teses da área. Suas pesquisas foram direcionadas a temas como: a relação da informação com o conhecimento e inovação na organização e na sociedade; a estrutura e o fluxo da informação e os seus estoques de acervamento de conteúdo e as novas formas de escrita e leitura no contexto das conexões imediatas. Além de significativa produção científica, publicada no Brasil e no exterior, Aldo Barreto deixou precioso legado para a área de Ciência da Informação no Brasil. 
Barreto ainda integrou o Grupo de Trabalho que editou o Livro Verde do Programa "Sociedade da Informação" do Ministério da Ciência e Tecnologia. Foi por mais de dez anos Chefe do Departamento de ensino e pesquisa do Ibict, com trabalhos publicados em periódicos de circulação nacional, internacional, livros e capítulos de livros. Registra-se, oportunamente, o fato de que, entre o início desta pesquisa e sua publicação, ocorreu o falecimento do professor Aldo Barreto, em fevereiro de 2018.

Com o objetivo de reconhecer a valorização de seu trabalho e a produção científica dele decorrente, assim como a influência que exerceu e vem exercendo sobre as posições dos pesquisadores descendentes, cujas atividades acadêmico-científicas estão oficialmente vinculadas ao pesquisador em foco, pretendeu-se também testar uma metodologia que possa ter seu alcance ampliado para outros estudos. A possibilidade desta pesquisa depende do modo de captação da realidade, portanto, está associada aos caminhos metodológicos a seguir enunciados, conjugando-se com os princípios de estudo sobre a genealogia científica.

Este artigo estrutura-se a partir desta seção introdutória, seguida de uma seção relativa à configuração teórica que o fundamentou, da descrição metodológica, dos resultados e das considerações finais.

\section{CONFIGURAÇÃO TEÓRICA DE REFERÊNCIA}

A proposta de analisar a consonância entre produção científica e suas origens genealógicas é estimulante, de modo especial para aqueles que procuram compreender como se processam, no espaço tempo da pesquisa, as relações entre orientadores e orientandos e os efeitos que elas produzem nas produções científicas.

Além disso, como argumenta Oliveira (1998, p. 19) a aproximação entre pesquisa e biografia é uma forma de atribuir vida ao estudo, retirando da produção intelectual o que ele denomina de "poeiras de artificialismo, que recobrem parte da pesquisa acadêmica (...)".

Considerando-se que a compreensão da produção científica requer condições necessárias para que se desenvolva o que foi denominado por Mills (1975) de "imaginação sociológica", neste artigo defende-se o movimento intelectual que, na concepção que se empresta do autor, "capacita seu possuidor a compreender o cenário histórico mais amplo, em termos de seu significado para a vida íntima e para a carreira exterior de numerosos indivíduos" (MILLS, 1975 p. 11). E esses indivíduos, aqui denominados de agentes porque não são sujeitos, mas atuam em favor de uma postura consciente como intelectuais críticos, ainda que não sejam sociólogos, como pesquisadores, orientadores ou em formação, estarão em condições de usar a informação e estimular a razão, a fim de "perceber, com lucidez, o que está ocorrendo no mundo e o que pode estar acontecendo dentro deles mesmos" (1975, p. 11).

Para compreender a ciência que se faz, portanto, não é suficiente a informação e os conteúdos que se adquirem sobre ela ou a habilidade da razão na utilização de métodos para compreendê-la, mas da imaginação sociológica Mills (1975, p. 11), caracterizada pela percepção entre biografia e história, entre indivíduos e estrutura.

Por meio de estudos genealógicos, orientados ao campo da produção e da comunicação científica, pode-se investigar a origem, evolução e permanência de autores e áreas do conhecimento, em prol da compreensão dos vínculos representados na literatura científica. Voltada a correntes teóricas ou metodológicas, recebidas, transmitidas e oriundas das relações entre agentes pesquisadores, essa vertente intelectual dos estudos métricos apresenta especificidades na literatura das áreas científicas. Por um lado, ela reflete um tipo de relação peculiar, representando um tipo de "afinidade eletiva", demonstrada durante a trajetória de 
um pesquisador ao selecionar e citar, por meio direto ou indireto, autores seminais ou fundantes para sua produção.

Essas relações são perceptíveis por meio de estudos como o de Montoye e Washburn (1980) sobre a genealogia acadêmica, pelos quais se configura a herança erudita de um determinado grupo de pesquisadores. A influência de autores sobre a sua época e seus descendentes tem sido tema de sociólogos, com destaque em Bourdieu, para quem os elementos culturais e interacionistas influenciadores e formuladores do gosto, do interesse, das classificações sociais, das normas e valores, e seus desdobramentos são dotados de dimensões objetivas e simbólicas, influenciando as relações estabelecidas entre os agentes.

Assim compreendido, o conjunto de conhecimentos teóricos e especialmente metodológicos que a $\mathrm{Cl}$ reúne permite que ela se consolide como um campo com amplas opções de análise, considerando-se o campo como o local onde se produzem as aptidões e os interesses científicos, cuja tendência à conservação e à satisfação é movida por um processo dialético interminável (BOURDIEU, 1983).

Essa configuração científica assemelha-se aos traços das perspectivas biológica e social de uma família, cujos filhos advém de uma relação formal de orientação e as gerações vão se organizando em irmãos, pais, avôs e bisavôs que descendem da parentela de um acadêmico seminal, por isso a importação do termo genealogia (BUFREM, 2017).

Os delineamentos assim definidos têm sido mais ou menos participantes do concerto amplo da ciência que estudam e ajudam a consolidar. Há autores considerados seminais em suas áreas, seja porque repercutem sobre a produção de outros, permanecendo como inspiradores no interior de uma especialidade, seja porque inauguram uma teoria (BUFREM, 2017).

Assim, considera-se para este estudo, um professor orientador como um autor seminal, somente se ele for identificado como inaugural de uma corrente que o repercute. Há também o agente que se pode considerar como fundante, pela sua influência sobre conceitos, fundamentos e teorias intelectuais, sem fronteiras. Oliveira (1998) refere-se aos autores fundantes ou fundadores como aqueles que remetem a propostas originais, pois contribuem e fornecem um novo conhecimento.

Para este estudo foi adotado um software desenvolvido por um dos autores, fundamentado em experiências de laboratório e em leituras de outros trabalhos. A pesquisa de Bornmann, Thor, Marx e Leydesdorff (2016), por exemplo, apresenta um software para examinar trabalhos seminais ou raízes históricas de pesquisas em diferentes campos científicos.

O software Mathword, possibilitou em seu algoritmo examinar as raízes históricas de campos diversos, em fase de protótipo, foi desenvolvido com base em propostas anteriores do grupo de pesquisadores relativas a análises de referências, tentando ampliar as possibilidades dos estudos bibliométricos e utilizando medições de impacto para campos específicos. Em sua proposta de análises de citações, eles propõem extrair todas as referências citadas a partir de um conjunto de publicações específicas para cada campo e analisar quais documentos (cientistas ou periódicos) foram citados com mais frequência e em quais anos.

Outras pesquisas do gênero vêm estimulando a criatividade para acompanhar os avanços científicos e tecnológicos mais recentes, como motivações para o desenvolvimento dessa imaginação sociológica, que se manifesta também na percepção entre conhecimentos e as estruturas e facilidades tecnológicas que os favorecem e impulsionam.

\section{METODOLOGIA}


Para o desenvolvimento da genealogia acadêmica de $A B$, na intenção de incluí-lo em uma linha de autores a ele relacionados e verificar com quais aquele cientista dialogou e com base na formação e produção dos campos de interesse, podem ser utilizados métodos e técnicas bibliométricas e cientométricas, como análises de cocitação, resgatando o referencial teórico utilizado por $A B$ e seus orientandos de doutorado. Essa prática tem sido um dos principais indicadores para medir a influência e verificar o impacto dos autores de referência citados sobre os trabalhos produzidos pelos descendentes de uma linhagem acadêmica.

Para a identificação dos orientandos de Aldo Barreto (AB) recorreu-se ao Currículo Lattes, com última atualização em 12/10/2016, no campo orientações concluídas de doutorado. Foram identificados e listados 15 pesquisadores titulados, entre 1992 e 2009. Com base nessa lista, foram resgatadas todas as produções de $A B$ e de seus orientandos de doutorado indexadas na Base Brapci. Justifica-se o uso da Brapci por indexar 63 revistas e mais de 22.000 trabalhos compreendidos entre os anos de 1972 e 2020, e pela possibilidade de indexar as referências dos artigos para análise de citação. Quanto à seleção dos orientandos de doutorado, deve-se ao aprofundamento das reflexões atingido nesse nível, caracterizado pelo reconhecimento de construções teóricas fundantes.

Para a identificação, utilizou-se o estudo de citação e cocitação, que segundo Grácio e Oliveira (2013), propicia visualizar mais claramente as temáticas abordadas e os autores que abordam tais assuntos, e a frequência com que esses autores aparecem concomitantes em determinada pesquisa.

Para identificar as referências dos trabalhos recorreu-se aos artigos completos na Brapci, com a conversão dos PDF em formato texto, de forma a possibilitar a recuperação e a organização das referências. Com a seleção dos trabalhos de cada pesquisador, foi possível identificar e transcrever as referências realizadas, em arquivo no formato texto.

Para extração das palavras mais frequentes, em texto completo, utilizou-se a técnica de indexação automática, mais especificamente a mineração de texto para extração de informações sobre tendências ou padrões em grandes volumes documentais. A indexação automática é uma operação que identifica, por meio de programas de computador, palavras ou expressões significativas dos documentos, para descrever de forma condensada o seu conteúdo (MAIA; SOUZA, 2010). Essas técnicas foram aplicadas a cada um dos arquivos individualmente, obtendo-se as palavras incidentes no texto e suas frequências.

Ao total, foram localizadas 2.480 referências nos trabalhos de $A B$, das quais, foram identificados 153 autores citados com duas ou mais citações. A mesma metodologia foi utilizada na bibliografia dos orientados, utilizando-se a metodologia para comparação de texto matchword (coincidências de palavras) (SELKIRK, 1974), em um software desenvolvido pelos autores, que retorna às palavras comuns e a sua frequência quando comparado às referencias de dois autores. Com esses dados, foi gerada uma matriz dos autores citados por $A B$, e com base nos seus resultados, foi observada a coincidência ou não da relação entre as referências de seus orientandos e os autores. Os resultados dessa busca foram distribuídos em uma matriz assimétrica de 15×32, e foram apresentados posteriormente no Quadro 2.

\section{RESULTADOS}

Com base no currículo Lattes, pode-se identificar que $A B$ orientou 15 pesquisas de doutorado (Quadro 1), cujas primeiras defesas começaram em 1992, sendo a última em 2009, sendo 18 anos dedicados a formação de doutores na $\mathrm{Cl}$. A contribuição de $A B$ pode ser 
percebida pela formação de seu legado, a maioria atuando em instituições de ensino no país, dos quais, quatro são ou foram bolsistas produtividade. Ressalta-se que Nilton Bahlis dos Santos, atualmente pesquisado da Fundação Oswaldo Cruz (Fiocruz), foi orientado duas vezes pelo professor $A B$, uma em seu doutorado na UFRJ e outra em seu período sanduíche na Universidad de Oviedo, tendo também como orientador o prof. Pablo Navarro.

Outro destaque é dado aqui a todos os orientados do professor $A B$ que seguiram a carreira acadêmica ou de pesquisa, com exceção da Ana Maria de Morais, cujo currículo não foi localizado na plataforma Lattes, pressupondo-se seu afastamento da academia.

Quadro 1 - Orientações de doutorado do Professor Aldo Barreto (1992-2009)

\begin{tabular}{|r|l|c|c|c|}
\hline \multicolumn{1}{|c|}{ \# } & \multicolumn{1}{|c|}{ Doutorado } & $\begin{array}{c}\text { Ano Dou- } \\
\text { torado }\end{array}$ & \multicolumn{1}{|c|}{ Local } & Bolsista \\
\hline 1 & Ana Maria de Morais (AM) & 1992 & Ibict/UFRJ & \\
\hline 2 & Maria Nelida Gonzalez de Gomez (GG) & 1992 & Ibict/UFRJ & Pq 1A \\
\hline 3 & Regina Maria Marteleto (RM) & 1992 & Ibict/UFRJ & Pq 1A \\
\hline 4 & Gilda Olinto de Oliveira (GO) & 1993 & Ibict/UFRJ & Pq 1C \\
\hline 5 & Katia Maria Coelho de Carvalho Custódio (KC) & 1995 & Ibict/UFRJ & \\
\hline 6 & Carlos Henrique Marcondes de Almeida (CM) & 1998 & Ibict/UFRJ & Pq 1D \\
\hline 7 & Lucia Thereza Lessa Carregal (LC) & 1998 & Ibict/UFRJ & \\
\hline 8 & Luiz Carlos Brito Paternostro (LP) & 1998 & Ibict/UFRJ & \\
\hline 9 & Maria Cristina Soares Guimarães (MC) & 1998 & Ibict/UFRJ & \\
\hline 10 & Nelson de Castro Senra (NS) & 1998 & Ibict/UFRJ & \\
\hline 11 & Antônio Cláudio Brasil Gonçalves (AG) & 2003 & lbict/UFRJ & \\
\hline 12 & Joana Coeli Ribeiro Garcia (JG) & 2004 & Ibict/UFRJ & \\
\hline 13 & Gustavo Henrique de Araújo Freire (GF) & 2004 & Ibict/UFRJ & Pq 2 \\
\hline 14 & Nilton Bahlis dos Santos (NB) & $2004 / 05$ & Ibict/UFRJ & \\
\hline 15 & Claudio Starec (CS) & 2009 & Ibict/UFF & \\
\hline
\end{tabular}

* Orientação de Doutorado Sanduiche.

Fonte: Lattes de Aldo Barreto

Procedido o levantamento de produção e das citações dos trabalhos dos pesquisadores, o resultado da comparação entre as citações de $A B$ e de seus orientandos possibilitou, não somente, a identificação dos autores utilizados pelo professor, como também a identificação da influência de outros autores nesse grupo de orientandos e a evolução de sua construção teórica predominante. A lista de autores citados e a frequência das citações recebidas constituem a matriz apresentada na Quadro 2. Na busca pelos trabalhos na Brapci, não foram encontradas produções da orientanda AM, totalizando 14 orientados analisados.

$\mathrm{Na}$ análise do Quadro 2, percebe-se o predomínio de Levy e Bourdieu ambos citados por nove dos 14 orientandos, seguidos por Mueller e o próprio Barreto, por oito orientados, e Solla Price, por sete. Entretanto na perspectiva das citações, Levy foi o mais citado, com 61 citações, seguido de Habermas, Bourdieu, Wersig, Barreto e Foucault. 


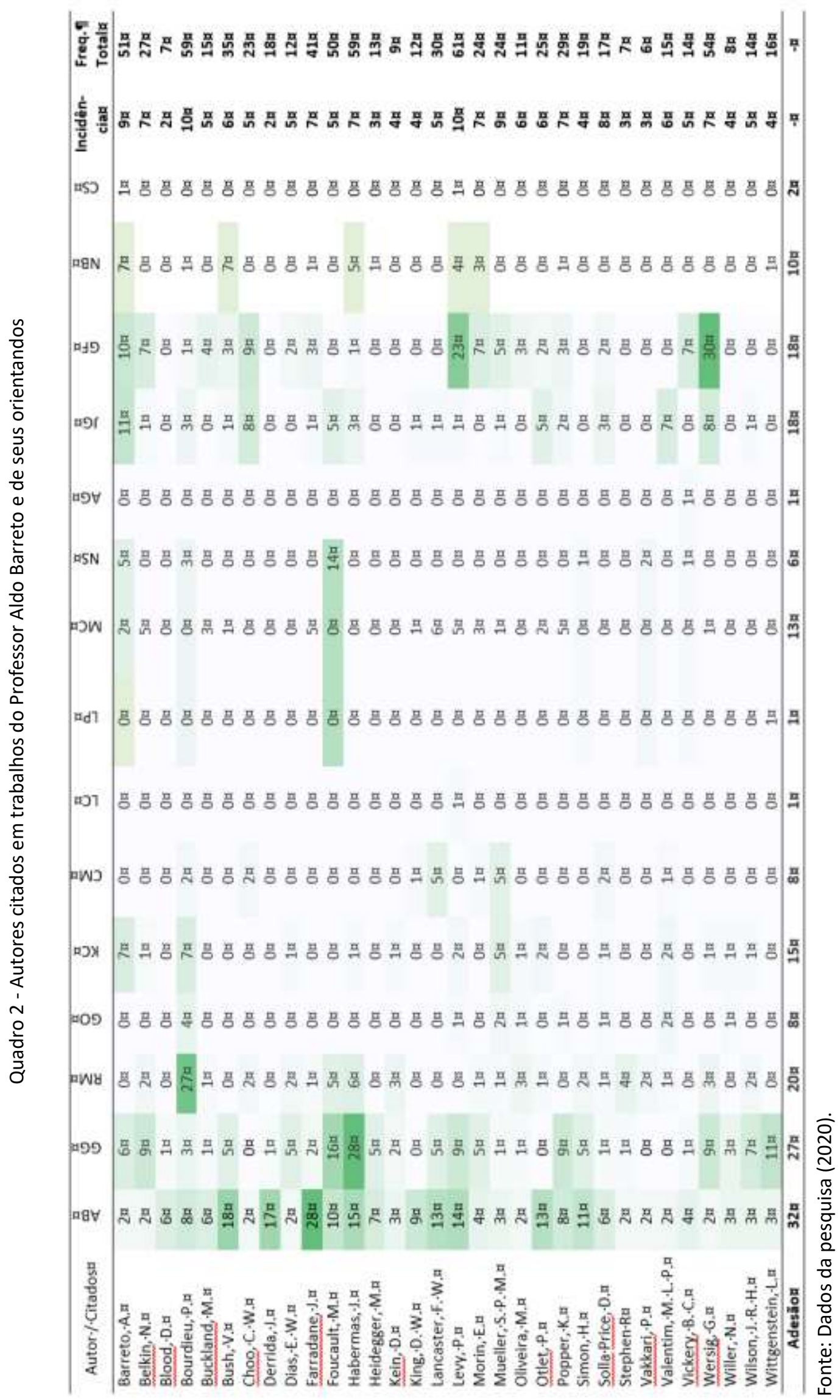


O prestígio científico de Levy manifesta-se quase exclusivamente em GF, com 23 citações, concedendo ao autor o que Bourdieu (2013) chamaria de notoriedade intelectual institucionalizada, graças ao poder ou autoridade manifesto pela direção de uma equipe de pesquisa, como a originada desse ramo de pesquisadores com seus descendentes e que inclui também a influência de Wersig, o quarto autor mais citado pelo universo. Quanto à influência de Habermas em GG, com 28 citações, mostra a aderência da autora à concepção habermasiana da pragmática formal, relacionada à passagem de um estudo que partia dos usos da linguagem para uma reconstrução de suas condições, sob um ponto de vista sociológico.

Bourdieu, um dos autores mais citados, predominantemente por RM, com 27 incidências, sugere a preferência da orientanda ao quadro conceitual do autor. Percebe-se, assim, o aprofundamento teórico e identificação da pesquisadora com Bourdieu, conforme sua trajetória intelectual. É possível caracterizar a influência de Bourdieu na formação do grupo analisado, por suas nuances de preferência e permanência de autores entre os mais citados, pois foi referenciado por dez, entre os 13 autores citantes orientandos de $A B$.

Os resultados corroboram o reconhecimento de que Bourdieu é considerado o sociólogo mais representativo e influente do nosso tempo, tanto no âmbito das ciências sociais quanto no das humanidades, tanto no interior da academia quanto para além dela (BURAWOY, 2010, p. 12).

O quinto autor mais referenciado foi Foucault, cuja presença é expressiva nos trabaIhos de GG e NS, de modo a superar as citações do orientador. Percebe-se, portanto, como certos autores passam a ser fundantes para os agentes descendentes, uma vez inscritos e por eles representados nas práticas de pesquisa e seus resultados. Essa influência foucaultiana é destacada por Buschman (2010, p. 4), para quem o autor tem sido amplamente citado e seus conceitos adaptados em diversos trabalhos que focam, dentro da Ciência da Informação, "as relações de poder, discurso, arqueologia, silêncios, exclusões, conceito de 'outro', dominação e micropráticas nos últimos 15 anos de teoria crítica da $\mathrm{BCl}$ ". Pode-se considerálo, portanto, como um autor fundante para o campo da $\mathrm{Cl}$.

O autor mais citado (28 vezes) por AB foi Farradane (1906-1989), seu orientador de mestrado. O nome de Farradane está historicamente relacionado à teoria dos indexadores relacionais, aplicada às descrições conceituais na área de classificação e indexação. Inspirado no modelo psicológico das estruturas do intelecto de Guilford, Farradane trabalhou com o pressuposto da existência de mecanismos universais de representação de conceitos pelos indivíduos (JACOB; SHAW, 1998).

A indexação relacional, por ele postulada, é descrita como modo de expressar as relações com base nos mecanismos do pensamento para serem convertidas diretamente em notações de indexação" (FARRADANE, 1980, p. 267-268). Entretanto, Farradane não teve a mesma repercussão entre os orientandos de $A B$, considerando-se que sete de seus filhos acadêmicos o citaram entre uma e três vezes. Apenas CM o citou cinco vezes. Do mesmo modo, a importância dada a Vannevar Bush (criador do Memex), citado por AB 18 vezes no corpus analisado, é compreensível devido ao aprofundamento das questões que ele passa a levantar em relação à aplicação de tecnologias revolucionárias à área, sobretudo o computador (BARRETO, 2007) e a evolução da Web.

Derrida, o terceiro autor mais citado por AB (17 vezes), principalmente quando trata do conhecimento como reconstrução das estruturas mentais, por meio de competências cognitivas que alteram o estado de conhecimento do indivíduo, tampouco teve repercussão entre seus orientandos. 
Salienta-se, entre os orientandos, uma afinidade mais explícita em termos de adesão aos citados por parte de GG, que referencia $27(84,4 \%)$ dos 32 autores de AB. Com uma aderência de 20 autores $(65,2 \%)$ RM apropria-se principalmente do referencial de Bourdieu, enquanto GF e JG, com aderência de 18 autores (56,3\%), volta-se a uma perspectiva pósmoderna, com Levy e Wersig. Percebe-se, também, o movimento que se poderia denominar como autonomia teórica dos orientandos em relação ao orientador, pela qual eles passam a expressar suas preferências pessoais, prestigiando autores e quadros teóricos participantes de um outro universo, com outros interesses e outros critérios, em relação aos quais os anteriores passam a ser secundarizados, visto que apenas quatro orientandos trabalham mais de $50 \%$ dos autores de AB. Entretanto, tal como defende Bourdieu (2013, p. 200-201), a tese doutoral permite aos professores um controle durável sobre os aspirantes à sucessão, em função das injunções ou apelos do orientador de tese.

Percebe-se, desse modo, que há autores citados com menor frequência pelo orientador e que adquirem maior protagonismo para seu descendente, como no caso de Wittgenstein. Referenciado por $A B$ em relação à transferência da informação para que o conhecimento opere, o autor tem o espectro das discussões que desenvolve na sua obra ampliado por GG, o que se reflete não apenas na maior frequência de citações, mas no conteúdo diversificado dos aspectos com que trabalha nos seus textos. Um desses aspectos é a realidade dos receptores e uma conjuntura de apropriação desta informação pelo indivíduo, contribuindo para que esse momento seja único, subjetivo e privado ao qual, Wittgenstein (1981) atribui solenidade.

Os resultados sugerem que as citações aos textos teóricos não podem ser analisadas isoladamente, pois devem ser relacionadas ao contexto mais abrangente dos grupos ou instituições em que se inserem. Assim, o que determina as relações de produção em um campo é a ação dos agentes e dos grupos, constituídos e constituintes das relações de força, ao investirem em suas pesquisas, cujo desdobramento e permanência são consoantes à economia particular do campo. Além das relações aparentes, neste caso da família genealógica aqui analisada, importa reconhecer como o sistema de relações se desdobra entre os elementos, como um sistema de relações objetivadas nas produções dos agentes, que nem sempre têm consciência das estruturas sobre as quais repousam o seu pensamento e o seu discurso (BOURDIEU, 1990, p. 23).

Portanto, é possível perceber o sentido desse corpus analisado "no conjunto dos trabalhos publicados por um autor ao longo de vários anos, percorrendo vários temas e elementos de reflexão, desenvolvendo sobretudo a sua lógica global de reflexão e, muitas vezes, alterando esta lógica" (GUIBENTIF, 2007, p. 90).

Para desenvolver o Cluster da Figura 1, utilizou-se a matriz assimétrica do Quadro 2, relacionando todos os elementos. O tamanho de cada circulo dos autores (nodes) representa a frequência de incidência, e a largura das linhas que interliga cada círculo, o número de ligações (edges). O gráfico foi gerado no VOSviewer.

A distribuição e a multidisciplinariedade perceptíveis no mapeamento da trajetória de $A B$ podem ser observadas na Figura 1. Nota-se que, entre os orientados, o mais próximo dos referenciais de AB é GG, como explicitado no Quadro 2.

Ao analisar a Figura 1, pode-se observar uma linha que aproxima autores de tendência pós-moderna, em azul, centrada principalmente em GF e FG, tendo como principais representantes deste agrupamento autores como Wersig, G.; Otlet, P e Choo, C. W. 
Figura 1 - Agrupamento (cluster) dos orientandos e dos autores citados por $A B$

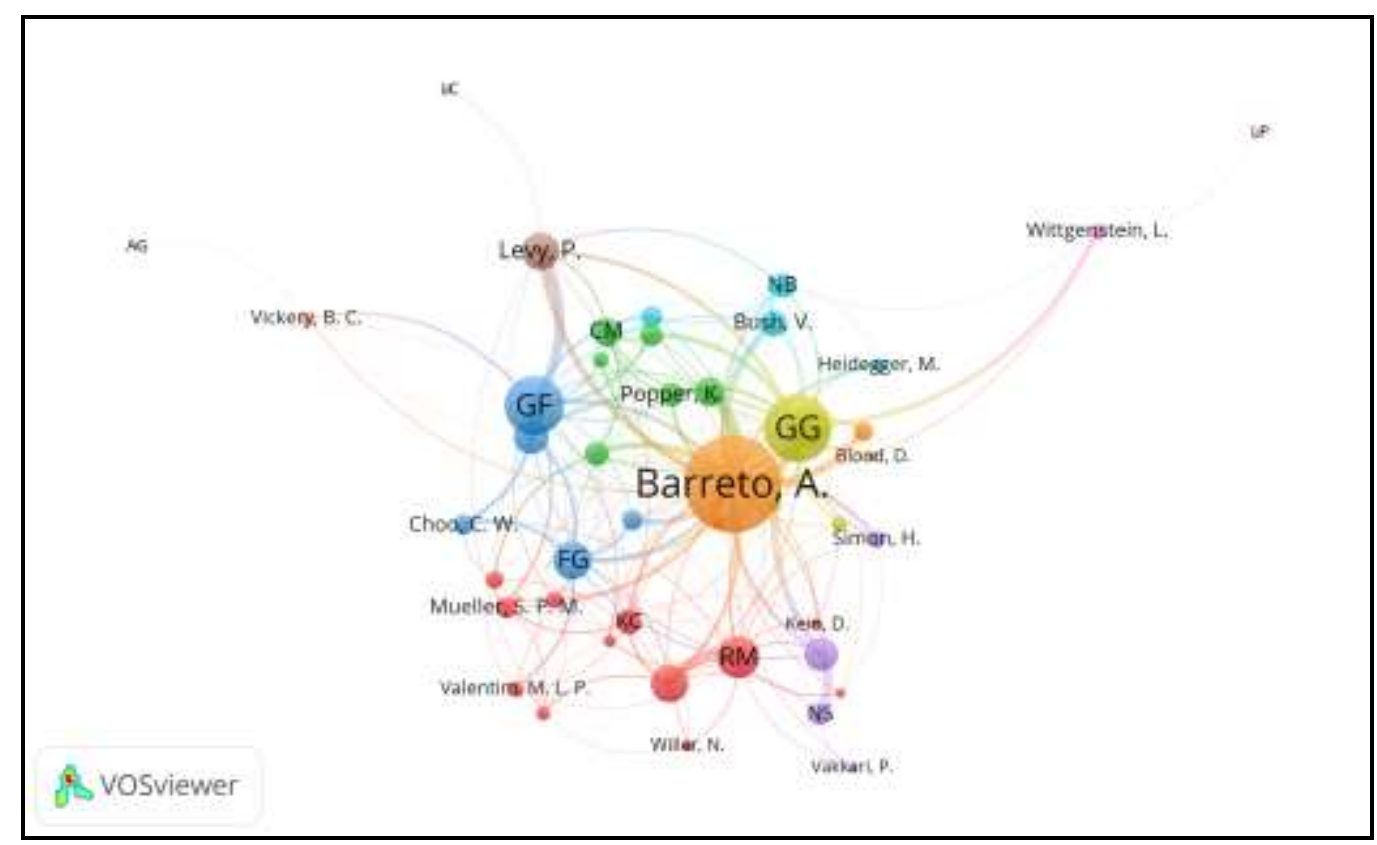

Fonte: Dados da pesquisa

O maior agrupamento formado é centrado em RM, KC, GO e MG. Constituindo-se como um grupo social, dele fazem parte Bourdieu, P.; Kein, D. Mueller, S. P. M.; Oliveira, M.; Solla Price, D. Stephen, R. Valentim, M. L. P. e Willer, M.

Um grupo, formado pelos estudos do documento e da informação, é composto por $\mathrm{CM}$ e alguns autores como Belkin, N., Buckland, M.; Farradane, J.; Lancaster, F. W.; e Popper, $\mathrm{K}$.

GG forma um cluster voltado à sociologia da ciência, com destaque para o estudo de questões epistemológicas, éticas e políticas da informação, e prioridade para a problemática relativa aos temas ação e regimes de informação e, como mencionado anteriormente, a que mais se aproximou dos autores de $A B$.

Outro cluster é centralizado por NS, relacionando teorias de Michel Foucault, sobre poder e conhecimento com as teorias da organização de Simon, H. aplicadas aos conceitos da biblioteconomia e Ciência da Informação de Pertti Vakkari.

Outro agrupamento formado por NB, Vannevar Bush, Martin Heidegger e Edgar Morin forma uma configuração temática variada entre filosofia, sociologia e tecnologia, buscando uma integração, como descrito no Lattes de NB, entre Tecnologias, Cultura e Práticas Interativas e Inovação.

AG, LC e LP foram os descendentes que mais se distanciaram do grupo central de AB. Ao analisar o currículo desses orientados, observou-se que AG e LC têm o foco em comunicação, sendo seus trabalhos alinhados às áreas de comunicação e jornalismo. Enquanto isso, $L P$, vinculado às tecnologias, tem pouca publicação registrada em seu currículo Lattes, ou seja, sua dedicação é voltada ao ensino e produção tecnológica, sem ter um engajamento na pesquisa. 


\section{CONSIDERAÇÕES FINAIS}

Esse trabalho é um reconhecimento ao Professor Aldo Albuquerque Barreto, pesquisador da elite da produção científica no país. Com resultados decorrentes da análise dos elos da corrente genealógica, foi possível reconhecer parcialmente a influência da atuação concreta do pesquisador em relação a sua descendência, por meio dos estudos de produção científica.

Desse modo, considera-se sua condição de ator seminal, ou seja, aquele que por sua atuação e influência constituiu-se como marco para seus descendentes, que adotaram, a partir de suas orientações, posições conceituais e terminológicas e enfoques de implementação que contribuíram para o conhecimento científico do campo em que atuou.

Foi possível também experimentar uma metodologia fundamentada nas relações entre os autores seminais, cujas teorias, conceitos e métodos serviram de base para os estudos da linhagem científica e dos princípios da genealogia científica.

Sobre as bases intelectuais, verifica-se a influência das obras de Farradane, Bush, Derrida, Habermas, Levy, Lancaster, Otlet, Simon e Foucault, autores mais referenciados por $A B$. Percebe-se o peso da literatura internacional como referencial do grupo, destacando-se o próprio $A B$ e Mueller, entre os autores nacionais. Estudos como este são relevantes para aferir sobre a influência mútua entre a genealogia científica e seus referentes acadêmicos, sobre a evolução e disseminação dos temas e áreas do conhecimento privilegiados e as opções metodológicas selecionadas. Confirma-se, desse modo, o valor dos estudos genealógicos no contexto acadêmico, especialmente quando relacionados aos componentes teóricos seminais que os orientam. Planeja-se, em decorrência da aplicação dessa modalidade de estudo, realizá-la com foco em outros pesquisadores produtividade do CNPq.

\section{AGRADECIMENTOS}

O presente trabalho foi realizado com apoio do Conselho Nacional de Desenvolvimento Científico e Tecnológico - Processo 308477/2016-2 Agradecimento a Rosane Teles Lins CastiIho por suas contribuições na biografia do Prof. Aldo Barreto.

\section{REFERÊNCIAS}

ANDRAOS, J. Scientific genealogies of physical and mechanistic organic chemists. Canadian Journal of Chemistry, Ottawa, v. 83, n. 9, p. 1400-1414, 2005.

BARRETO, A. Mitos e lendas da informação: o texto, o hipertexto e o conhecimento.

DataGramaZero, v. 8, n. 1, fev. 2007.

BORNMANN, L.; THOR, A.; MARX, W.; LEYDESDORFF, L. Identifying seminal works most important for research fields: software for the Reference Publication Year Spectroscopy (RPYS), COLLNET Journal of Scientometrics and Information Management, v. 10, n. 1, p. 125140, 2016. DOI: 10.1080/09737766.2016.1177948.

BOURDIEU, P. O campo científico. In: ORTIZ, R. Pierre Bourdieu. São Paulo: Editora Ática, 1983. (Coleção Grandes Cientistas Sociais). 
BOURDIEU, P. Capital simbólico e classes sociais. Novos Estudos-CEBRAP, n. 96, jul. 2013.

BOURDIEU, P. Razões práticas: sobre a teoria da ação. São Paulo: Papirus, 1996.

BUFREM, L. S. Quadros teóricos seminais na prática da pesquisa em Ciência da Informação no Brasil. Projeto de pesquisa de Bolsa de Produtividade em Pesquisa do Conselho Nacional de Desenvolvimento Científico e Tecnológico (CNPq), 2017.

BURAWOY, M. O marxismo encontra Bourdieu. Org. Ruy Gomes Braga Neto. Campinas, SP: Ed. da Unicamp, 2010.

BUSCHMAN, J. Transgredir ou estagnar? Desafiando Foucault na teoria da Biblioteconomia e Ciência da Informação (BCl) Transgression or stasis? Challenging Foucault in LIS Theory. InCID: R. Ci. Inf. e Doc., Ribeirão Preto, v. 1, n.1, p. 3-31, 2010.

FARRADANE, J. Relational indexing. Part I. Journal of Information Science, n.1, p. 267-276. 1980.

GRÁCIO, M. C. C., OLIVEIRA, E. F. T., \& MATOS, G. I. Visibilidade dos pesquisadores no tema Estudos Métricos: análise de citação e cocitação nos periódicos do SciELO. IBERSID: revista de sistemas de información y documentación, v. 3, p. 75-80, 2009

GUIBENTIF, P. Teorias sociológicas comparadas e aplicadas: Bourdieu, Foucault, Habermas e Luhmannface ao Direito. Cidades, Comunidades e Territórios, Lisboa, n. 14, p. 89-104, Jun. 2007.

JACOB E. K; SHAW D. Sociocognitive perspectives on representation. Annual review of information science and technology, v. 33, p. 131-185, 1998.

MAIA, L. C. G.; SOUZA, R. R. Uso de sintagmas nominais na classificação automática de documentos eletrônicos. Perspectivas em Ciência da Informação, v. 15, n. 1, p. 154-172, 2010.

MENA-CHALCO, J. P. Genealogia acadêmica: uma ferramenta para investigar a origem, evolução e disseminação de áreas do conhecimento. In: ENCONTRO BRASILEIRO DE BIBLIOMETRIA E CIENTOMETRIA, 5., 2016, São Paulo. [Workshop] . São Paulo: ECA/USP, 2016.

MILLS, C. Wright. A imaginação sociológica. 4 ed. Rio de Janeiro: Zahar, 1975. MONTOYE, H. J.; WASHBURN, R. Research Quarterly contributors: An academic genealogy. Research Quarterly for Exercise and Sport, v. 51, n. 1, p. 261-266, 1980.

OLIVEIRA, Paulo Salles. caminhos de construção da pesquisa em ciências humanas. In: OLIVEIRA, P. S. Metodologia das Ciências Humanas. São Paulo: Hucitec, 1998.

PUC-RJ. Rio Datacentro: relatóro anual. Rio de Janeiro: PUC/RJ, 1972. Relatório. 
ROSSI, L.; MENA-CHALCO, J. P. Caracterização de árvores de genealogia acadêmica por meio de métricas em grafos. In: Congresso da Sociedade Brasileira de Computação, 34., 2014, Brasília. Anais [...] Brasília: SBC, 2014. p. 21-32.

SELKIRK, E. French liaison and the X' notation. Linguistic Inquiry, v. 5, p. 573- 590, 1974.

WITTGENSTEIN, L. Zettel, Lisboa: Edições 70, 1981. 